UDC 343.1:343.271

LBC 67.410 .206

\title{
THE LEGAL NATURE OF A JUDICIAL FINE AND THE PROSPECTS OF LARGE-SCALE DECRIMINALIZATION OF CRIMINAL ACTS ${ }^{1}$
}

\author{
Lyubov V. Lobanova \\ Volgograd State University, Volgograd, Russian Federation
}

\begin{abstract}
Introduction: the paper highlights some problems concerning the inter-sectoral differentiation of responsibility and the responsibility in criminal law arising in connection with the introduction of a new ground for exemption from criminal responsibility into the domestic legislation (Article 762 of the Criminal Code). The goals and objectives are to determine the nature of a court fine and the immediate prospects of decriminalization of criminal acts punishable by the death penalty. Methods: the authors used the traditional methods of cognition of legal phenomena. Results: the author analyzed the viewpoints of the scientists, not perceiving the very idea of exemption from criminal responsibility with replacing it by another enforcement action and proposing to decriminalize the acts which can be punishable be a court fine. There are studied the possibilities of a total "cleansing" of the Criminal Code. Attention is drawn to the basis of the inter-sectoral differentiation of responsibility and its difference from the grounds of the differentiation of responsibility in criminal law. There are highlighted some of the shortcomings of the mentioned ideas relating to the definition of the legal nature of a new treatment of offenders. Scope of application: it is designed for use in the legislative and law enforcement practice, and research. There were drawn the conclusions about the impossibility of large-scale decriminalization of socially dangerous acts, in respect of which it is possible to use Article 762 of the Criminal Code, and the inappropriate exclusion from the Criminal Code of the Russian Federation of a new kind of exemption from responsibility, and the need of its transformation in the exemption from criminal responsibility with its replacement by the administrative measures and referring to the ones of a court fine.

Key words: inter-sectoral differentiation of responsibility, differentiation of criminal responsibility, social danger of an act, court fine, decriminalization of acts.
\end{abstract}

УДК 343.1:343.271

ББК 67.410 .206

\section{ПРАВОВАЯ ПРИРОДА СУДЕБНОГО ШТРАФА И ПЕРСПЕКТИВЫ МАСШТАБНОЙ ДЕКРИМИНАЛИЗАЦИИ ПРЕСТУПНЫХ ДЕЯНИЙ ${ }^{1}$}

\author{
Любовь Валентиновна Лобанова \\ Волгоградский государственный университет, г. Волгоград, Российская Федерация
}

Введение: в статье освещаются некоторые проблемы, касающиеся межотраслевой дифференциации ответственности и ответственности в уголовном праве, возникшие в связи с введением в отечественное законодательство нового основания освобождения от уголовной ответственности (ст. $76^{2}$ УК РФ). Целями и задачами выступают выяснение природы судебного штрафа и определение ближайших перспектив декриминализации преступных деяний, за которые указанная мера может быть применена. Методы: в процессе работы использованы традиционные методы познания юридических явлений. Результаты: проанализиро․ ваны позиции ученых, не воспринимающих саму идею освобождения от уголовной ответственности с заме궁 ной ее какими-либо иными мерами воздействия и предлагающих декриминализировать деяния, за которые ضे возможно применение судебного штрафа. Изучены возможности такой тотальной «чистки» Уголовного кодекса. Обращено внимание на основание межотраслевой дифференциации ответственности и его отличие от оснований дифференциации ответственности в уголовном праве. Подчеркнуты некоторые недостатки выражения в законе упомянутой идеи, касающиеся определения юридической природы новой меры воздействия на преступников. Область применения: предназначено для использования в законодательной и правоприменительной практике, а также научной работе. Сформулированы выводы о невозможности масштаб- 
ной декриминализации общественно опасных деяний, в связи с которыми возможно применение ст. $76^{2}$ УК РФ, и нецелесообразности исключения из УК РФ нового вида освобождения от ответственности, а также о необходимости его преобразования в освобождение от уголовной ответственности с заменой ее мерами административного воздействия и отнесении к последним судебного штрафа.

Ключевые слова: межотраслевая дифференциация ответственности, дифференциация уголовной ответственности, общественная опасность деяния, судебный штраф, декриминализация деяния.

\section{Введение}

Ежегодно в России многомиллионная «армия» судимых лиц пополняется сотнями тысяч «новобранцев». Такой вывод позволяет сделать анализ соответствующих данных, которыми располагает Судебный департамент при Верховном Суде Российской Федерации. Так, только за шесть месяцев 2016 г. было осуждено 266182 лица, не имеющих до этого неснятых и непогашенных судимостей. Из них лишь 9315 человек были освобождены от наказания по приговору суда, то есть судимости не приобрели (ч. 2 ст. 86 УК РФ) [5].

На фоне подобных цифр вполне понятны усилия государства, направленные на минимизацию числа граждан, обремененных указанным неблагоприятным статусом, накладывающим отпечаток не только на жизнь их самих, но и их близких. Ведь за такого рода показателями прослеживается изменение отнюдь не в лучшую сторону качественной структуры социума, поскольку в последнем неизменно увеличивается тем самым доля лиц с ограниченными законодательством, регламентирующим последствия судимости, возможностями.

Этими устремлениями объясняются и декриминализация некоторых деяний, и приобретение отдельными уголовно-правовыми нормами качества норм с административной преюдицией, и конструирование нового основания освобождения от уголовной ответственности, закрепленного в ст. $76^{2}$ УК РФ. Последняя статья Уголовного кодекса, а также статьи УК и УПК РФ, призванные обеспечить функционирование основания освобождения от уголовной ответственности с назначением судебного штрафа (см. ст. $104^{4}, 104^{5}$ УК РФ, ст. $25^{1}, 446^{1}-446^{5}$ УПК), активно подвергаются научному анализу, причем в основном критическому.

Среди упреков, адресованных законодателю, особенно выделяются те, которые выз- ваны абсолютным непринятием самой идеи освобождения от уголовной ответственности с заменой ее иными мерами воздействия, будто бы нарушающей Конституцию РФ, принципы уголовного и уголовно-процессуального права.

\section{О перспективах масштабной} декриминализации преступных деяний

Отдельных ученых беспокоит то обстоятельство, что к лицу, не признанному виновным обвинительным приговором суда, применяется штраф, являющийся мерой уголовноправового характера, размер которой устанавливается в соответствии с определенной статьей УК РФ (см.: [3, с. 90-91]). Не возражая в целом против гуманизации и либерализации уголовного законодательства, но подвергая вместе с тем резкой критике положения закона, относящиеся к прекращению уголовного дела с освобождением от уголовной ответственности с назначением судебного штрафа, авторы подобных доводов предлагают отечественному законодателю несколько выходов из сложившейся ситуации, в числе которых рекомендация о декриминализации части преступных деяний. «Если, по мнению законодателя, совершаются преступления, ответственность за которые возможна в виде штрафа, то может быть было бы целесообразным перевести такие правонарушения в категорию административных?»-спрашивает, например, А.П. Кругликов [3, с. 91].

Но в том-то и дело, что столь масштабная декриминализация ныне признаваемых преступными деяний, осуществляемая в русле межотраслевой дифференциации ответственности, невозможна.

Заметим, что еще в советское время некоторые специалисты обращали внимание на то, что перевод общественно опасных деяний в разряд проступков отнюдь не может быть достойной заменой существовавшему в 
тот период освобождению от уголовной ответственности в связи с привлечением к административной. При этом справедливо подчеркивалась значительность доли преступлений, за которые допускался данный вид освобождения от уголовной ответственности в общей массе преступных деяний, а также существенность суммарного вреда, который подобные посягательства причиняли обществу [2, c. 146].

Освобождение от уголовной ответственности лиц, совершивших социально одобряемые поступки после своего преступления, в том числе и на основании ст. $76^{2}$ УК РФ, затрагивает гораздо более широкий круг преступных деяний, чем освобождение от уголовной ответственности, осуществлявшееся на основании ст. $50^{1}$ УК РФ. Оно возможно в отношении целых двух категорий преступлений небольшой и средней тяжести. Зададимся вопросом: готово ли наше государство и общество к декриминализации деяний, конструкции которых занимают лидирующее место в структуре Особенной части УК РФ? Ведь в последнем не так уж много статей, устанавливающих уголовную ответственность исключительно за тяжкие и особо тяжкие преступления (по приблизительным нашим расчетам, $1 / 7$ часть). Да и в структуре судимости львиная доля принадлежит судимости за преступления небольшой и средней тяжести. Так, из лиц, осужденных судами РФ за упомянутый в начале нашей работы период (379034 человека), 193858 человек осуждены за преступления небольшой тяжести и еще 86538 человека - за преступления средней тяжести [5].

Отрицательный ответ на поставленный вопрос представляется очевидным. Если основания для дальнейшего существования каких-либо уголовно-правовых запретов изначально отсутствовали или были утрачены, то это касается единичного числа норм.

Конечно, нельзя не видеть сходства между оптимизацией межотраслевой дифференциации ответственности и углублением дифференциации ответственности в уголовном праве, ибо в том, и в другом случае ставится задача максимально использовать потенциал средств, не являющихся уголовным наказанием, для реагирования на деяния, обладающие изрядной вредоносностью, то есть такой, к которой государство не может относиться безразлично. Однако основания межотраслевой дифференциации принципиально отличаются от тех обстоятельств, из которых исходит законодатель, ранжируя правовые последствия содеянного с помощью средств одной отрасли права. Лишение деяния того или иного вида статуса преступного посягательства с переводом его в разряд правонарушений иной отраслевой принадлежности оправданно лишь в случае, если типичный уровень его общественной опасности позволяет отказаться от такого средства их (деяний) предупреждения, как угроза применения наказания, и в то же время требует установления мер с менее интенсивным выражением карательного содержания (мер административного воздействия, мер гражданской или дисциплинарной ответственности и т. п.). Как показывает практика, судебный штраф сегодня применяется за деяния, характер общественной опасности которых вряд ли соответствует уровню общественной опасности, типичному для деяний, эффективное предупреждение которых способны обеспечить иные, чем уголовное, отрасли российского законодательства (кражи (ч. 1 ст. 158); мошенничество, квалифицируемое по ст. $159^{1}, 159^{2}$; нарушение правил безопасности движения и эксплуатации транспортных средств лицами, управляющими транспортными средствами (ст. 264); злоупотребление должностными полномочиями (ч. 1 ст. 285) и др.).

Следовательно, в отношении них и подавляющего большинства других преступлений небольшой или средней тяжести и речи быть не может о том, чтобы исключить применение за их совершение уголовного наказания. Но вполне допустимо рассуждать о возможности реагирования на определенные случаи подобных деяний с помощью иных мер. Ведь согласно УК РФ (ч. 1 ст. 6) справедливость наказания и иных мер уголовно-правового характера определяется соответствием не только характеру, но и степени общественной опасности преступления, а также обстоятельствам его совершения и личности виновного.

Сконструировав новое основание освобождения от уголовной ответственности, законодатель обратился, на наш взгляд, к более рациональному на данный момент способу 
коррекции репрессивных начал уголовного права, чем декриминализация. Не вмешиваясь в основания уголовной ответственности за общественно опасные деяния, относимые к определенным категориям, он попытался углубить ее дифференциацию и тем самым заполнить пустоту, образовавшуюся между реализацией уголовной ответственности и полным отказом от применения каких бы то ни было мер воздействия на преступника при освобождении от уголовно-правового обременения, на основании ст. 75 и 76 УК РФ путем закрепления такого вида освобождения, который связан с назначением судебного штрафа. А в итоге, надо полагать, ожидалось уточнение границ индивидуального подхода к совершенным преступлениям и лицам, их совершившим.

В самой идее освобождения от уголовной ответственности с заменой ее иными мерами воздействия нет ничего опасного для принципов уголовного права. Другое дело, что при нормативном закреплении такого основания освобождения не сработала законодательная техника.

\section{О правовой природе судебного штрафа}

Пожалуй, один из самых неясных вопросов касается юридической природы самого судебного штрафа - той меры, которая назначается освобождаемому в соответствии со ст. $76^{2}$ УК РФ лицу. Казалось бы, принадлежность судебного штрафа к иным мерам уголовно-правового характера очевидна. Это с определенностью следует из места расположения данной статьи в системе Общей части УК, поскольку соответствующая глава $-15^{2}$ «Судебный штраф» - помещена в раздел VI Уголовного кодекса, носящий название «Иные меры уголовно-правового характера». Однако сомнения в этом уже высказаны в юридической науке. «Вслед за законодателем, - пишет И.Э. Звечаровский, - судебный штраф можно было бы считать мерой уголовно-правового характера, применяемой вне механизма реализации уголовной ответственности $<\ldots>$ Дело однако в том, что судебный штраф, исполняемый после освобождения от уголовной ответственности, лишен какого-либо уголовно-правового значения. Судебный штраф, применяемый как мера уголовно-правового характера, сохраняет это качество лишь до момента своего исполнения, судебный штраф не может считаться мерой уголовно-правового характера - он реализован за рамками уголовно-правовых отношений» [1, с. 100]. Приведем еще одну выдержку из цитируемой работы. «За что платит судебный штраф лицо, $<\ldots>$ если оно уже возместило ущерб или иным образом загладило причиненный вред? Ответ напрашивается такой: за освобождение от уголовной ответственности. Могут возразить, что оно уже состоялось. Вопрос: тогда за что платит лицо, освобожденное от уголовной ответственности?» [1, с. 100].

Мы не во всем склонны согласиться с И.Э. Звечаровским. Во-первых, применительно к иным мерам уголовно-правового характера не вполне корректна постановка проблемы «За что?», поскольку таковые применяются не всегда «за», в ряде случаев «в связи с совершением общественно опасного деяния». И в этом плане неясности нет: судебный штраф применяется в связи с совершением преступления небольшой или средней тяжести. Вовторых, освобождение от уголовной ответственности по ст. $76^{2}$ УК РФ условно, поскольку опасность реализации уголовной ответственности, включая применение уголовного наказания, сохраняется вплоть до полной уплаты судебного штрафа (ч. 2 ст. $104^{4}$ УК РФ). А это значит, что до окончания исполнительного производства уголовно-правовые отношения вовсе не прекращаются, а реализуются, хотя и в весьма специфическом содержании. В-третьих, заглаживание причиненного преступлением вреда, включая возмещение ущерба, нанесенного виновным, выполняет компенсационную функцию и вовсе не исчерпывает нейтрализации всех вредных последствий содеянного. Еще остается тот урон, который лицо нанесло самому себе. А потому существует потребность в искуплении вины (разумеется, если отсутствуют менее обременительные для субъекта основания уголовной ответственности), а следовательно, и потребность в возвращении лица в состояние, при котором оно не будет совершать преступлений.

Вместе с тем в размышлениях указанного автора немало резонного. Прежде все- 
го необходимо подчеркнуть, что природу судебного штрафа действительно сложно понять, не имея четкого представления об основании реализации именно данного вида освобождения от уголовной ответственности. Для его [основания] характеристики мало знать, в связи с чем применяется судебный штраф, не в меньшей мере важно представлять, для достижения каких целей он применяется. А вот эти-то цели законодатель почему-то и не попытался определить. Подобный упрек в адрес законодателя уже звучал в юридической печати. Вносились и соответствующие предложения по коррекции ст. $76^{2}$ УК РФ в части оснований ее реализации [4, с. 112-115; 6, c. 127].

Кроме того, в определении законодателем правовой природы судебного штрафа действительно есть какое-то противоречие. Если это иная мера уголовно-правового характера, то почему она не лишена негативных признаков, которые отличают подобные меры от наказания: отсутствие четкого выражения карательного содержания, невключенность в перечень уголовных наказаний? Ведь даже размер денежного взыскания в принципе сопоставим с размером штрафа как вида уголовного наказания, поскольку «ополовинивание» объема кары, заложенного в санкции статьи, устанавливаемой за конкретное преступление, в связи с которым лицо освобождается от уголовной ответственности, вовсе не препятствует назначению штрафа в том размере, в каком он в том или ином случае может быть назначен за данное преступление в качестве уголовного наказания. На наш взгляд, двойственность природы судебного штрафа может быть преодолена лишь путем отказа от отнесения его к иным мерам уголовно-правового характера. В Уголовном кодексе должен предусматриваться только один вид денежного взыскания, обладающего карательным содержанием: штраф как мера уголовного наказания. Иначе определенность теряют не только понятие «иная мера уголовноправового характера», но и фундаментальная категория уголовного права - «уголовное наказание». Самым приемлемым вариантом решения данной проблемы является возвращение в уголовное законодательство такого вида освобождения от уголовной ответствен- ности с заменой ее мерами административного воздействия. Позаимствовав многое из соответствующей статьи последнего УК РСФСР (см. ст. $50^{1}$ ), инициаторы конструирования нового основания освобождения от уголовной ответственности напрасно отказались от отнесения меры, заменяющей в рассматриваемом случае реализацию уголовной ответственности, к мерам административного воздействия. Ведь данный вид освобождения прекрасно зарекомендовал себя в советское время. На это указывали и востребованность данного института на практике, и его положительное влияние на уровень фактического рецидива преступлений.

Заданный объем статьи препятствует нам обозначить контуры предстоящих новаций.

\section{Выводы}

1. Декриминализация общественно опасных деяний, осуществленная в последние годы, и введение нового основания освобождения от уголовной ответственности (ст. $76^{2}$ УК РФ) мотивированы одним и тем же стремлением законодателя минимизировать в структуре российского общества долю судимых лиц.

2. Масштабная декриминализация преступных деяний, осуществляемая в русле межотраслевой дифференциации ответственности, в настоящее время невозможна. Соответственно с помощью ее нельзя безболезненно отказаться от института освобождения от уголовной ответственности с назначением судебного штрафа.

3. Лишение деяний того или иного вида статуса преступления с переводом их в разряд правонарушений иной отраслевой принадлежности оправданно в случае, если типичный уровень его общественной опасности позволяет отказаться от такого средства их (деяний) предупреждения, как угроза уголовного наказания, и в то же время требует установления мер с менее интенсивным выражением кары. Этого нельзя сказать о большинстве видов преступлений, в отношении которых может применяться судебный штраф. Но вполне возможно рассуждать о допустимости реагирования на некоторые случаи с помощью иных мер, включая судебный штраф. 
4. В самой идее освобождения от уголовной ответственности с заменой ее иными мерами воздействия нет ничего опасного для принципов уголовного права. Однако ее воплощение в действующем УК РФ небезукоризненно. Неудачно определена природа судебного штрафа. К иным мерам уголовно-правового характера отнесено взыскание, обладающее ярко выраженным карательным содержанием. В результате утрачена правовая определенность не только понятия «иные меры уголовно-правового характера», но и категории «наказание». Для преодоления подобной неопределенности необходимо вернуть в российское законодательство освобождение от уголовной ответственности с заменой ее мерами административного воздействия.

\section{ПРИМЕЧАНИЕ}

${ }^{1}$ Статья подготовлена при поддержке гранта Российского гуманитарного научного фонда. Проект № 17-03-00720.

\section{СПИСОК ЛИТЕРАТУРЫ}

1. Звечаровский, И. О юридической природе судебного штрафа (ст. 76 2 , $104^{4}$ УК РФ) / И. Звечаровский // Уголовное право. - 2016. - № 6. - С. 98-101.

2. Коган, В. М. Социальный механизм уголовно-правового воздействия / В. М. Коган. - М. : Наука, 1983. -183 с.

3. Кругликов, А. П. Некоторые вопросы, возникающие при анализе положений введенной в УПК РФ главы $51^{1}$ : «Производство о назначении меры уголовно-правового характера при освобождении от уголовной ответственности» / А. П. Кругликов // Библиотека криминалиста. - 2017. - № 1 (30). - С. 88-92.

4. Лобанова, Л. Некоторые проблемы установления и реализации нового основания освобождения от уголовной ответственности / Л. Лобанова, С. Мкртчян // Уголовное право. - 2016. - № 6. C. 111-121.

5. Отчет о числе привлеченных к уголовной ответственности и видах уголовного наказания за 6 месяцев 2016 года. - Электрон. текстовые дан. - Режим дос- тупа: http://www.cdep.ru/index.php?id=79\&item=3834 (дата обращения: 05.06.2017). - Загл. с экрана.

6. Юсупов, М. Вопросы применения нового вида освобождения от уголовной ответственности с назначением судебного штрафа / М. Юсупов // Уголовное право. - 2016. - № 6. - С. 122-128.

\section{REFERENCES}

1. Zvecharovskiy I. O yuridicheskoy prirode sudebnogo shtrafa (st. 762, 1044 UK RF) [On the Legal Nature of Judicial Penalty (art. 762, 1044 of the Criminal Code of the Russian Federation)]. Ugolovnoe pravo, 2016, no. 6, pp. 98-101.

2. Kogan V.M. Sotsialnyy mekhanizm ugolovnopravovogo vozdeystviya [Social Mechanism of Criminal Law Influence]. Moscow, Nauka Publ., 1983. $183 \mathrm{p}$.

3. Kruglikov A.P. Nekotorye voprosy, voznikayushchie pri analize polozheniy vvedennoy v UPK RF glavy $51^{1}$ : «Proizvodstvo o naznachenii mery ugolovno-pravovogo kharaktera pri osvobozhdenii ot ugolovnoy otvetstvennosti» [Some Issues Arising from the Analysis of the Provisions of Chapter 511 "Proceedings on Appointment of the Measure of CriminalLegal Nature when Exempting from Criminal Liability", Included in the Criminal Procedure Code]. Biblioteka kriminalista, 2017, no. 1(30), pp. 88-92.

4. Lobanova L., Mkrtchyan S. Nekotorye problemy ustanovleniya i realizatsii novogo osnovaniya osvobozhdeniya ot ugolovnoy otvetstvennosti [Certain Problems of Introduction and Implementation of a New Ground to Release from Criminal Liability]. Ugolovnoe pravo, 2016, no. 6, pp. 111-121.

5. Otchet o chisle privlechennykh $k$ ugolovnoy otvetstvennosti $i$ vidakh ugolovnogo nakazaniya za 6 mesyatsev 2016 goda [Report on People Brought to Criminal Responsibility and the Types of Criminal Punishment for 6 Months of 2016]. URL: http:// www.cdep.ru/index.php?id=79\&item $=3834$. (accessed June 5, 2017).

6. Yusupov M. Voprosy primeneniya novogo vida osvobozhdeniya ot ugolovnoy otvetstvennosti s naznacheniem sudebnogo shtrafa [The Application of a New Type of Exemption from Criminal Liability with the Appointment of a Judicial Fine]. Ugolovnoe pravo, 2016, no. 6, pp. 122-128. 


\section{Information about the Author}

Lyubov V. Lobanova, Doctor of Juridical Sciences, Professor, Head of the Department of Criminal Law, Volgograd State University, Prosp. Universitetsky, 100, 400062 Volgograd, Russian Federation, lobanova@volsu.ru.

\section{Информация об авторе}

Любовь Валентиновна Лобанова, доктор юридических наук, профессор, заведующая кафедрой уголовного права, Волгоградский государственный университет, просп. Университетский, 100, 400062 г. Волгоград, Российская Федерация, lobanova@volsu.ru. 